\title{
METODOLOGIAS PARA MENSURAÇÃO DO CAPITAL INTELECTUAL: balanço intelectual
}

\author{
Benedito Geovani Martins de PAIVA ${ }^{1}$
}

Neusa Maria Bastos Fernandes dos SANTOS²

${ }^{1}$ Doutorando em Administração da Pontifícia Universidade Católica de São Paulo - PUC-SP. E-mail: benedito.geovani@yahoo.com.br

2Professora do Programa de Doutorado em Administração da Pontifícia Universidade Católica de São Paulo - PUC-SP. E-mail: admneusa@pucsp.br

Recebido em: 15/12/2016 - Aprovado em: 26/06/2017 - Disponibilizado em: 01/07/2017

\section{RESUMO}

O presente artigo em tem o objetivo sugerir uma metodologia de mensuração do Capital Intelectual para compor as Demonstrações Contábeis tradicionais. A Ciência Contábil vem ao longo do tempo pesquisando diversos métodos para a mensuração do capital intelectual, mas apesar de todo o avanço ainda existem poucos instrumentos para evidenciar, analisar e disponibilizar aos usuários das informações contábeis, o valor do capital intelectual. Uma das grandes dificuldades de mensuração do capital intelectual está nas características de subjetividade e volatilidade. Capital Intelectual representa a capacidade do indivíduo em aplicar o conhecimento nas mais diversas situações bem como sua capacidade de inovar e transformar ideias em produtos, serviços ou mesmo processo. Surge assim a questão problema que norteou o presente artigo: Existem métodos para cálculo do valor do capital intelectual? A metodologia utilizada foi a pesquisa bibliográfica na literatura disponível, nos estudos já publicados em livros, revistas, jornais e periódicos que abordam o tema "capital intelectual", especificamente métodos e/ou modelos para a sua mensuração. Entre os métodos destacados pela literatura o que melhor atende aos objetivos do artigo é o de Skandia. Esse modelo abrange indicadores sob o foco financeiro, humano, do cliente, do processo, e da renovação e desenvolvimento. Cabe aos profissionais de Contabilidade estudos adicionais a respeito do método proposto para mensuração do Capital Intelectual.

Palavras chave: Capital Intelectual. Contabilidade. Modelo de Skandia. Subjetividade. Volatilidade.

\section{METHODOLOGIES FOR MEASUREMENT OF INTELLECTUAL CAPITAL: intelectual balance}

\begin{abstract}
The purpose of this article is to suggest a methodology for measuring Intellectual Capital to compose the traditional Financial Statements. Accounting Science has over the years been researching several methods for measuring intellectual capital, but despite all the progress, there are still few instruments to evidence, analyze and make available to users of accounting information the value of intellectual capital. One of the biggest difficulty of measuring intellectual capital lies in the characteristics of subjectivity and volatility. Intellectual Capital represents the individual's ability to apply knowledge in the most diverse situations as well as their ability to innovate and transform ideas into products, services or even process. This raises the problem question that guided this article: Are there methods for calculating the value of intellectual capital? The methodology used was the bibliographical research in the available literature, in studies already published in books, magazines, newspapers and periodicals that approach the theme "intellectual capital", specifically methods and/or models for their measurement. Among the methods highlighted in the literature, the one that best meets the objectives of the article is the method of Skandia. This model encompasses indicators under the financial, human, customer, process, and renewal and development focus. It is incumbent upon Accounting professionals to further study the proposed method for measuring Intellectual Capital.

Keywords: Intellectual Capital. Accounting. Model of Skandia. Subjectivity. Volatility.
\end{abstract}




\section{INTRODUÇÃO}

Os ativos intelectuais tornaram-se elementos importantes no mundo dos negócios; responsáveis pelo desempenho e vantagem competitiva das empresas frente a um mercado cada vez mais exigente. Nesse contexto, a mensuração do capital intelectual passa a despertar interesses tanto do mundo acadêmico quanto empresarial, dada sua relevância para o valor de uma organização, considerado por muitos empresários como um dos seus principais ativos. A Ciência Contábil vem ao longo do tempo pesquisando diversos métodos para mensurar, evidenciar, analisar e disponibilizar aos usuários das informações contábeis o valor do capital intelectual. Mas apesar de todo o avanço, ainda existem poucos instrumentos.

O valor de uma empresa é representado por ativos tangíveis e intangíveis, que geram benefícios futuros. A dificuldade para apurar o valor contábil mais próximo do valor de mercado está na mensuração do ativo intangível, sendo o capital intelectual um item de sua composição. A adoção das Normas Internacionais de Contabilidade representou um avanço na Ciência Contábil como fornecedora de informações econômicas e financeiras para a tomada de decisão. Porém, a Ciência Contábil ainda carece de metodologias adequadas para mensurar e apresentar, nos Demonstrativos Contábeis, o valor do capital intelectual.
Assim, tem-se a questão norteadora deste artigo: Existem métodos para mensurar o valor do capital intelectual de uma empresa? Tem-se como objetivo sugerir uma metodologia de mensuração do Capital Intelectual para compor as Demonstrações Contábeis tradicionais. A metodologia utilizada foi a pesquisa bibliográfica na literatura disponível, nos estudos já publicados em livros, revistas, jornais e periódicos que abordam o tema "capital intelectual", especificamente métodos e/ou modelos para a sua mensuração. $\mathrm{O}$ artigo se justifica diante do crescimento da sociedade do conhecimento, dos investimentos em educação e treinamento contínuo que estão mudando os paradigmas empresariais e a forma de valorizar uma empresa, fatores esses que representam vantagem competitiva.

$\mathrm{O}$ artigo encontra-se estruturado em cinco partes, sendo a primeira apresenta a introdução; a segunda, os conceitos de capital intelectual; na terceira, as normas de contabilidade e a mensuração do capital intelectual; na quarta, os modelos de mensuração do Capital Intelectual; e na quinta, a sugestão do Balanço Intelectual para complementar as Demonstrações Contábeis.

\section{CAPITAL INTELECTUAL}

O Capital Intelectual pode ser definido como um conjunto de valores e conhecimentos de uma empresa que lhe proporciona vantagem competitiva no 
mercado. Constitui a matéria intelectual como conhecimento, informações, experiências e propriedade intelectual. Apresenta a característica de intangibilidade, não podendo ser tocado, porque não possui existência física, mas agrega valores reais à organização.

O capital intelectual é um intangível formado pelas habilidades, capacidades, expertise, culturas, lealdade, dentre outros. Estes se constituem em ativos do conhecimento mais importantes do que os ativos tangíveis para determinar o sucesso ou fracasso de uma empresa. Entre os obstáculos encontrados pela Ciência Contábil para a mensuração do capital intelectual, destacamse a subjetividade, volatilidade e intangibilidade, fatores de difícil mensuração por não possuírem existência física. Além dessas características, destacam-se a inconstância, pois não existe garantia da sua permanência na empresa, recurso ilimitado. Essa prerrogativa significa que o reconhecimento compartilhado permanece com o funcionário e, ao mesmo tempo, enriquece a empresa com a utilização do capital intelectual. Surge nesse contexto alguns questionamentos como: onde encontrálos? Quem os possui? Quais os responsáveis por sua gestão? (MALHOTRA, 2005; STEFANO et. al., 2014; STEWART, 2002).

Assim, o capital intelectual representa a capacidade do indivíduo em aplicar o conhecimento nas mais diversas situações, bem como sua capacidade de inovar e transformar ideias em produtos, em serviços ou mesmo em processo (DOYLE; O'CONNOR, 2013).

Já Bassan e Hauschildt (2005) corroboram que o capital intelectual é formado por três tipos de capital: humano, estrutural e de clientes. O capital humano representa toda capacidade, conhecimento, habilidade e experiência individuais dos empregados e proprietários para criação e desenvolvimento de produtos e serviços inovadores para atrair e satisfazer os clientes da melhor maneira possível. O estrutural compreende os ativos intangíveis relacionados com a estrutura e os processos de funcionamento interno e externo da empresa; permanece na organização empresarial quando os empregados vão para casa. Já o de cliente refere-se ao relacionamento contínuo com pessoas e organizações para as quais a empresa mantém relação comercial.

A mensuração do capital humano envolve vários fatores como o nível de formação, competência, participação, motivação e integração com os objetivos da empresa. Capital Estrutural é um ativo estratégico para vantagem competitiva, composto por ativos não humanos, tais como: sistemas de informação, rotinas, procedimentos e bases de dados. O Capital de Clientes é toda estrutura externa de relacionamento com os clientes e fornecedores disponibilizados pela empresa, inter-relacionados para compartilhar conhecimento com o cliente. (AFONSO, 
2013; BONTIS E FITZENZ, 2002; STEFANO et. al., 2014; SHARABATI, JAWAD E BONTIS, 2010; STEWART, 1998; WADONGO; KAMBONA E ODHUNO, 2011).

A compreensão das distinções de Capital Humano, Capital Estrutural e Capital de Cliente são imprescindíveis para a gestão de seu conhecimento da empresa. Para os fins deste estudo, Capital Intelectual é definido como a matéria intelectual, ou seja, conhecimento, informação, propriedade intelectual, experiência, que pode ser utilizada para gerar riqueza. E, isso pode se dar por meio das habilidades, experiência e conhecimento de seus funcionários.

\section{NORMAS DE CONTABILIDADE E MENSURAÇÃO CAPITAL INTELECTUAL}

A convergência das Normas Brasileiras de Contabilidade às Normas Contábeis Internacionais iniciou-se, a partir da Lei n. ${ }^{\circ} 11.638 / 07$ e consolidou-se com Lei n. ${ }^{\circ}$ 11.941/09, gerando mudanças no cenário contábil brasileiro. No que se refere aos Ativos Intangíveis, de acordo com Carvalho e Lemes (2010), foi editado o Comitê de Pronunciamento Contábil 04 (CPC 04) definindo parâmetros para a mensuração, contabilização da amortização e das perdas por impairment. Para que possa ser considerado um Ativo Intangível é necessário que item atenda aos três itens estabelecidos no conceito de Ativo Intangível, ou seja, sejam identificáveis, controlados e geradores de benefícios futuros.

Niyama (2010) relata que as demonstrações contábeis devem evidenciar o valor agregado dos gastos com pesquisas e desenvolvimento reconhecido como despesa durante o período. De acordo com os conceitos contábeis, se um ativo intangível proporciona benefícios, faz-se necessário criar mecanismos para apropriá-lo ao capital e ao resultado. É notável, por outro lado, a dificuldade que a contabilidade tradicional encontra em mensurar o valor, quanto o Capital intelectual representa para uma empresa.

A literatura, tanto das Normas Internacionais quanto das Brasileiras de Contabilidade, não relata como mensurar e contabilizar o Capital Intelectual. O desafio para a classe contábil consiste em introduzir, nas Demonstrações Contábeis tradicionais, parâmetros para evidenciar, medir e mensurar o verdadeiro valor do Capital Intelectual. As Normas Internacionais de Contabilidade não oferecem um modelo para tal mensuração, ficando assim, a cargo da contabilidade criar e desenvolver técnicas que permitam que o Capital Intelectual seja mesurado e espelhado de forma clara, simples e objetiva. Uma economia só é forte quando as pessoas que a compõem são eficientes e capazes de agregarem valor aos produtos e serviços. 
4 MODELOS DE MENSURAÇÃO DO CAPITAL INTELECTUAL

A mensuração do capital intelectual é complexa tendo em vista a subjetividade contida no tema. Trata-se da atribuição de valor a itens que não podem ser vistos, nem tocados, mas que agregam valor por serem potenciais geradores de lucro ou riqueza. Cada empresa possui uma particularidade na mensuração de seus ativos intangíveis, o que é explicado pela grande diferenciação dos ativos das empresas.

Segundo Padoveze (2000), os ativos intelectuais são aqueles itens baseados em conhecimento, que a companhia possui. Podem ser adquiridos ou formados internamente, tem a característica de gerar fluxo de caixa presente e futuro para a empresa. A mensuração do capital intelectual, de certa forma, já vem sendo realizada pelo próprio mercado quando atribui valor a uma determinada empresa e é quase sempre bastante superior àquele encontrado nos registros contábeis.

O capital intelectual interfere diretamente no valor de uma empresa, o que, por sua vez, surge a necessidade de mensuração. Diversos modelos de avaliação têm sido recomendados pela literatura, tendo em vista a complexidade da questão e a inexistência de um instrumento à prova de contestações, inclusive pelas normas internacionais de contabilidade.
A seguir serão apresentados os principais modelos de mensuração do Capital Intelectual encontrados na literatura.

\subsection{Método da diferença entre valor de mercado e valor contábil}

A diferença entre o valor de mercado e o valor contábil é um dos indicadores mais utilizados para medir o capital intelectual. Por esse método, o valor do capital intelectual é determinado pela diferença entre valor contábil e valor de mercado (valor unitário de ação x n. $^{\circ}$ de ações) de uma empresa.

Niyama (2010) relata que um ponto desfavorável desse modelo seria o fato de que tanto o valor de mercado quanto o valor contábil podem estar subestimados, uma vez que ambos interferem no resultado. Este fato prejudica, de forma substancial, a mensuração do valor da empresa. Com a adoção das Normas Internacionais de Contabilidade, esse problema foi minimizado, uma vez que a empresa deve apresentar as demonstrações a valor de mercado.

O capital intelectual é calculado utilizando a seguinte equação:

- $\mathrm{CI}=\mathrm{VM}-\mathrm{VC}$.

Onde:

- $\mathrm{CI}=$ Capital intelectual.

- $\mathrm{VM}=$ Valor de mercado.

- $\quad \mathrm{VC}=$ Valor Contábil

Este método, voltado para área financeira, baseia-se nos valores expressos na Contabilidade com relação à diferença do 
valor de mercado da empresa para saber seu valor agregado.

\subsection{Método da razão entre o valor de} mercado e o valor contábil (ou Market-toBook)

O modelo Market-to-Book é conhecido como razão M/B. O valor do capital intelectual é resultante da divisão do valor de mercado das empresas pelo valor de seu Patrimônio Líquido. Gomes (2003, p.71) corrobora que nessa abordagem, "os intangíveis (capital intelectual) são expressos pela relação entre o valor de mercado e o valor contábil", conforme a seguinte equação: Capital intelectual $=$ Valor de Mercado / Valor Contábil do Patrimônio Líquido. Esse método é voltado para área financeira, cujo resultado é obtido por meio de um cálculo matemático simples. Devido à facilidade de cálculo, este método tem sido o mais difundido para a mensuração do capital intelectual.

\subsection{Modelo de mensuração do capital intelectual " $Q$ " de Tobin}

O Modelo de Mensuração do Capital Intelectual "Q" de Tobin é o índice do valor de mercado da empresa em relação ao custo de reposição de seus ativos, obtido pela adição da depreciação ao valor contábil.

Sousa e Pinho (2009, p.4) corroboram que o "Q é definido como a relação entre o valor de mercado da empresa e o custo de reposição de seus ativos físicos."

O "Q" de Tobim é calculado pela fórmula:

$$
\mathrm{q}=\frac{\mathrm{VMA}+\mathrm{VMD}}{\mathrm{VRA}}
$$

- VMA = valor de mercado das ações (ou capital próprio da firma);

- $\quad \mathrm{VMD}=$ valor de mercado das dívidas (ou capital de terceiros empregado);

- VRA = valor de reposição dos ativos da firma.

O resultado é uma variável que justifica os investimentos de capital nas empresas: Se q > 1 a opção é atrativa e se q < 1 a opção de investimento não é atrativa.

Na medida em que o "Q" movimentase para valores superiores a 1 , o mercado está atribuindo valores cada vez maiores aos intangíveis da empresa.

Gomes (2003, p.72) relata que, apesar de não ter sido desenvolvido para mensuração do capital intelectual, o " $\mathrm{Q}$ " de Tobim define o valor oculto da empresa, com relação ao seu valor de mercado quando esse divergir de seu valor contábil. Essa diferença é resultado dos investimentos em tecnologias e capital humano que geram ativos intangíveis agregadores de valor à empresa.

$O$ "Q" de Tobim pode ser calculado para ativos específicos, como veículos, máquinas, edificações, ou para empresa como um todo. Nas indústrias de software e tecnologia, onde o capital intelectual é 
abundante, o "Q" de Tobim tende para um número igual ou superior a 7 (sete) ou mais e nas companhias de capital físico, este indicador tende para valores aproximados de 1 (um)

\subsection{Modelo de Stewart}

Pelo modelo desenvolvido por Stewart (2002), denominado de "Navegador do Capital Intelectual", entende que o capital intelectual interfere diretamente no desempenho da empresa e deve ser analisado sob várias perspectivas, como, por exemplo, razão do valor de mercado/valor contábil, medidas de capital do cliente, medidas de capital humano e medidas de capital estrutural.

A figura 01 apresenta o Navegador do Capital Intelectual em forma de um gráfico de radar.

Figura 01 - Gráfico Radar: Navegador do Capital Intelectual

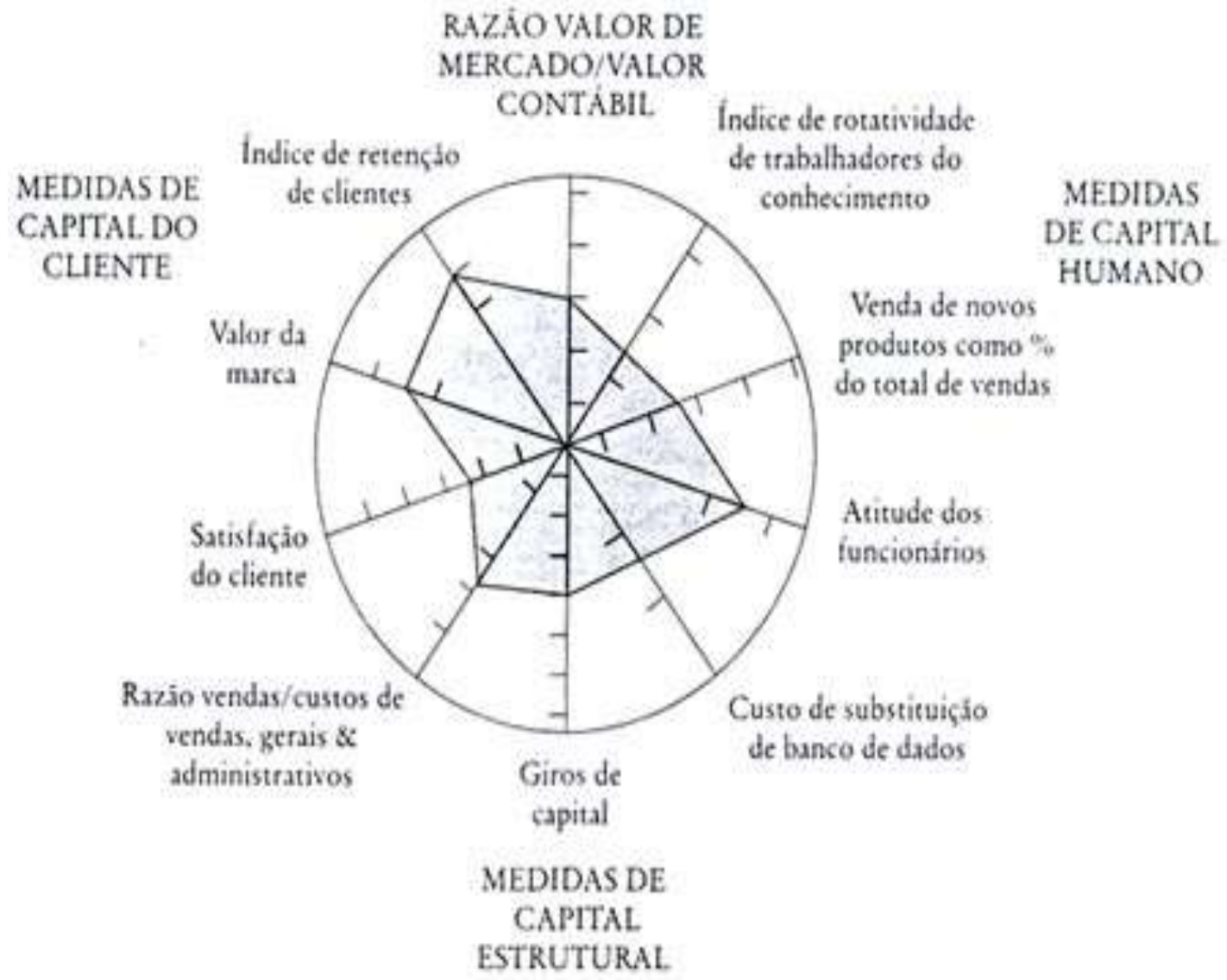

Fonte: Stewart (2002, p.219)

Ferreira (2004, p.6) corrobora que o "navegador do capital intelectual tem a vantagem de ser de fácil visualização e acompanhamento da evolução do desempenho da empresa". Deve-se ter cuidado na escolha dos índices de desempenho, para que sejam adequados à estratégia empresarial. Por abordar várias medidas, por meio de índices financeiros e não financeiros, para acompanhar o 
desempenho da empresa, o navegador proporciona uma clara visão dos pontos principais dentro da organização de acordo com a estratégia empresarial.

\subsection{Modelo Skandia}

A Skandia é uma grande empresa sueca do mercado de seguros e serviços financeiros e foi o primeiro grupo a divulgar um relatório contendo dados sobre o capital intelectual de suas unidades, como um suplemento das Demonstrações Contábeis de 1994.
Antunes (2000) explica que o Modelo de Skandia agrupou os fatores de sucesso em cinco áreas de focos distintos: financeiro, de clientes, de processo, de renovação e desenvolvimento e humano. A combinação dessas cinco áreas resulta em um relatório diferente, destacando diversos aspectos que dão o caráter dinâmico. Este relatório foi denominado de Navegador de Skandia.

A seguir, são apresentados os indicadores de Mensuração Absoluta do Capital Intelectual (C):

Quadro 01: Indicadores da Mensuração Absoluta do Capital Intelectual (C)

- Receitas resultantes da atuação em novos negócios.

- Investimento no desenvolvimento de novos mercados.

- Investimento no desenvolvimento do setor industrial.

- Investimento no desenvolvimento de novos canais.

- Investimento em Tecnologia da Informação (TI) aplicada a vendas, serviço e suporte.

- Investimento em TI aplicado à administração.

- Novos equipamentos de TI.

- Investimento no suporte aos clientes.

- Investimento no serviço aos clientes.

- Investimento no treinamento de clientes.

- Despesas com clientes não relacionadas ao produto.

- Investimento no desenvolvimento da competência dos empregados.

- Investimento em suporte e treinamento relativo a novos produtos para os empregados.

- Treinamento especialmente direcionado aos empregados que não trabalham nas instalações da empresa.

- Investimento em treinamento, comunicação e suporte direcionados aos empregados permanentes em período integral.

- Programas de treinamento e suporte especialmente direcionados aos empregados temporários de período integral.

- Programas de treinamento e suporte especialmente direcionados aos empregados temporários de tempo parcial.

- Investimento no desenvolvimento de parcerias/joint-ventures.

- Upgrades no sistema.

- Investimento na identificação da marca (logotipo/nome).

- Investimento em novas patentes e direitos autorais.

Fonte: Edvinsson e Malone (1998, p.173-174). 
Edvinsson e Malone (1998) mencionam que $(\mathrm{C})$ enfatiza o compromisso de uma empresa em relação ao futuro, ao passo que Índice do Coeficiente de Eficiência (i) do capital intelectual alicerça esse compromisso no desempenho atual.
A seguir, são apresentados os indicadores mais representativos de cada foco, expressos em porcentagens, quocientes e índices:

Quadro 02: Índice do Coeficiente de Eficiência ( $i)$ do Capital Intelectual

- Participação de mercado (\%).

- Índice de satisfação dos clientes (\%).

- Índice de liderança $(\%)$.

- $\quad$ Índice de motivação (\%).

- Índice de investimento em pesquisa \& desenvolvimento em relação ao investimento total $(\%)$.

- Índice de horas de treinamento (\%).

- Desempenho/meta de qualidade $(\%)$.

- Retenção dos empregados (\%).

- Eficiência administrativa dividida pelas receitas (\%).

Fonte: Edvinsson e Malone (1998, p.175).

Antunes (2000) explica que (i) é obtido por meio dos indicadores mais representativos de cada foco, expressos em porcentagens, quocientes e índices.

A equação sugerida para mensurar é i $=(\mathrm{n} / \mathrm{x})$, em que $\mathrm{n}$, é igual à soma dos valores decimais dos nove índices de eficiência, e o x é o número destes índices, ou seja, dele se obtém a média aritmética. A avaliação global do Capital Intelectual é resultante da multiplicação do índice (i) pela variável (C), conforme a seguinte equação: Avaliação do Capital Intelectual $=\mathrm{iC}$

Esta metodologia se destaca entre as demais, tendo em vista a abrangência dos indicadores utilizados, organizados sob o foco financeiro, humano, do cliente, do processo e da renovação e desenvolvimento.

Devido a diversidade das organizações fazem-se necessárias adaptações tais como: reavaliar a lista, incluindo demais pontos ou excluindo outros.

\subsection{Modelo de Sveiby}

Modelo de Sveiby (1998) apresenta as medidas de Capital Intelectual na forma de avaliação dos ativos intangíveis de uma empresa. Este modelo foi desenvolvido, na Swedish Comunity of Practice que, por meio de relatório anual, apresentou a evolução dos itens do capital intelectual.

Esta metodologia divide o Ativo da empresa em tangíveis e intangíveis, classificando-os em três grupos: competências 
das pessoas, estrutura interna e estrutura

externa, conforme demonstra quadro 03.

Quadro 03: Monitor de ativos intangíveis do Modelo de Sveiby

\begin{tabular}{|c|c|c|}
\hline \multicolumn{3}{|c|}{ MONITOR DE ATIVOS INTANGÍVEIS } \\
\hline Estrutura Externa & Estrutura Interna & Competência das Pessoas \\
\hline $\begin{array}{l}\text { Crescimento/Renovação } \\
\text { :Crescimento orgânico do } \\
\text { volume de vendas. } \\
\text { Aumento da participação } \\
\text { no Mercado. Índice de } \\
\text { clientes insatisfeitos ou } \\
\text { índice da qualidade. }\end{array}$ & $\begin{array}{l}\text { Crescimento/Renovação } \\
\text { Investimento: em } \\
\text { tecnologia da informação. } \\
\text { Parcela de tempo dedicada } \\
\text { às atividades internas de } \\
\text { P\&D. Índice de atitude do } \\
\text { pessoal em relação aos } \\
\text { gerentes, à cultura e aos } \\
\text { clientes. }\end{array}$ & $\begin{array}{l}\text { Crescimento/Renovação: } \\
\text { Parcela de vendas geradas } \\
\text { por clientes que aumentam } \\
\text { a competência. Aumento } \\
\text { da experiência média } \\
\text { profissional ( } \mathrm{n}^{\circ} \text { de anos). } \\
\text { Rotatividade } \\
\text { competência. }\end{array}$ \\
\hline $\begin{array}{ll}\text { Eficiência: Lucro por } \\
\text { cliente Vendas } & \text { por } \\
\text { profissional } & \end{array}$ & $\begin{array}{l}\text { Eficiência: Proporção de } \\
\text { pessoal de suporte Vendas } \\
\text { por funcionários de } \\
\text { suporte. }\end{array}$ & $\begin{array}{l}\text { Eficiência: Mudança do } \\
\text { valor agregado por } \\
\text { profissional. Mudança na } \\
\text { proporção de profissionais. }\end{array}$ \\
\hline $\begin{array}{l}\text { Estabilidade: Frequência } \\
\text { da repetição de pedidos } \\
\text { Estrutura etária }\end{array}$ & 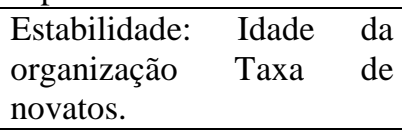 & $\begin{array}{llr}\text { Estabilidade: } & \text { Taxa } & \text { de } \\
\text { rotatividade } & & \text { dos } \\
\text { profissionais. } & & \\
\end{array}$ \\
\hline
\end{tabular}

Fonte: Sveiby (1998, p.238)

Modelo de Sveiby descreve medidas de avaliação da competência das pessoas, estrutura interna e externa. Classifica os ativos intangíveis em três categorias: indicadores de crescimento/renovação, indicadores de eficácia e indicadores de estabilidade. As medidas descritas são acompanhadas por meio de um monitor de ativos intangíveis. Não excedendo a uma página, o monitor pode ser integrado ao sistema de gerenciamento de informações acompanhado por comentários.

O modelo de Sveiby (1998) recebe o nome de Monitor de Ativos Intangíveis, no qual se propõe a classificação dos ativos intangíveis em grupos de três elementos: competência do funcionário, estrutura interna e estrutura externa. Para cada um destes grupos propostos é criado indicadores com foco no crescimento e renovação, eficiência e estabilidade.

\subsection{Modelo de Straiotto}

O modelo proposto por Straiotto (2000) sugere que os gastos com recursos humanos sejam lançados no Ativo da Empresa, na Conta Contábil "Investimento em ativos humanos" e amortizados para custos ou despesas, de acordo com os controles do departamento de Recursos Humanos. A seguir, o Balanço Sugerido por Straotto (2000): 
Quadro 04: modelo proposto por Straiotto

\begin{tabular}{|c|c|}
\hline \multicolumn{2}{|c|}{ BALANÇO PATRIMONIAL - EMPRESA X } \\
\hline ATIVO & PASSIVO \\
\hline Ativo Circulante & Passivo Circulante \\
\hline Ativo Realizável a Longo Prazo & Obrigações Trabalhistas e Sociais \\
\hline Ativo Não Circulante & \multirow{2}{*}{ Salários e Encargos Sociais } \\
\hline Ativo Imobilizado & \\
\hline Estrutura de apoio aos RHs & \multirow{2}{*}{$\begin{array}{l}\text { Nível } 1-\left(1^{\mathrm{a}} \text { a } 4^{\mathrm{a}} \text { série Ensino Fundamental }\right) \\
02 \text { Salários e Encargos sociais }\end{array}$} \\
\hline Depreciação Acumulada & \\
\hline Ativo de Investimento & \multirow{2}{*}{$\begin{array}{l}\text { Nível } 2 \text { - (Primário Completo) } \\
\text { 03 Salários e Encargos sociais }\end{array}$} \\
\hline Investimentos em RHs & \\
\hline Avaliação & \multirow{2}{*}{$\begin{array}{l}\text { Nível } 3-\text { (Ensino Médio e/ou Curso } \\
\text { Técnico) } \\
\text { 04 Salários e encargos sociais }\end{array}$} \\
\hline Reavaliação & \\
\hline Desvalorização & \multirow{2}{*}{$\begin{array}{l}\text { Nível } 4 \text { - (Graduação) } \\
\text { 05 Salários e encargos sociais }\end{array}$} \\
\hline Intangível & \\
\hline Gastos de Investimentos em RHs & \multirow{2}{*}{$\begin{array}{l}\text { Nível } 5 \text { - (Especializações em Geral) Passivo } \\
\text { Exigível a Longo Prazo }\end{array}$} \\
\hline Amortização de gastos em RHs & \\
\hline
\end{tabular}

Fonte: Adaptado de Straiotto (2000, p. 38 e 39)

Já no Passivo, o autor sugere detalhar o valor agregado da empresa em todos seus níveis de acordo com o grau de escolaridade dos funcionários, ou seja, o Capital Intelectual aplicado de cada nível ao produto ou serviço nas fases do ciclo operacional da empresa. Para tal, seria necessário abrir a conta salários no plano de contas da Contabilidade em níveis.

Este modelo não atende aos requisitos e recomendações das Normas Internacionais de Contabilidade quanto à acumulação dos gastos, realizado com a mão de obra, para geração de benefícios futuros. Estas devem ser lançadas diretamente na Demonstração de Resultado como despesa, enquanto o Modelo de Straitto (2000) sugere sua acumulação nas contas do Ativo.
Essa diferença dificultaria a operacionalidade desse modelo no dia a dia das empresas. Entretanto, quanto às sugestões para o Passivo, pode-se controlar e apresentar o perfil da mão de obra e o valor agregado pela mesma.

\section{SUGESTÃO DE MODELO DO BALANÇO INTELECTUAL}

As Normas Internacionais de Contabilidade introduziram uma reestruturação nas demonstrações contábeis tradicionais, principalmente da relação à harmonização, entre os valores contábeis e de mercado das empresas.

No entanto, "mensuração dos intangíveis é imprecisa e subjetiva" conforme defendido por Stewart (2002, p. 403). O 
grande desafio para os profissionais de contabilidade e finanças é desenvolver ou adaptar ferramentas para mensurar o capital intelectual, sabendo que o mesmo é extremamente volúvel e intangível.

O Balanço Intelectual proposto referese a uma demonstração complementar às demonstrações contábeis exigidas pela legislação. Deve ser elaborada pela controladoria em conjunto com o departamento de Recursos Humanos e apresentar o valor do Capital Intelectual aos Stakeholders, valor esse que deverá compor o valor de mercado da empresa.

Edvinsson e Malone (1998, p.174) advertem para que não seja aceita e utilizada essa lista como fórmula definitiva. Para isso, salientam que "ela foi feita com propósito único de debater o que constitui o Capital Intelectual”.

Os quadros 05 e 06 apresentam o exemplo prático do modelo de Skandia.

Quadro 05: Índices relacionados ao capital intelectual

\begin{tabular}{|c|l|c|}
\hline $\mathbf{N}^{\mathbf{0}}$ & Índices relacionados ao capital intelectual & $\mathbf{n}$ \\
\hline 1 & Participação de mercado $(\%)=$ & $68 \%$ \\
\hline 2 & Índice de satisfação dos clientes $(\%)=$ & $91 \%$ \\
\hline 3 & Índice de Liderança $(\%)=$ & $62 \%$ \\
\hline 4 & Índice de Motivação $(\%)=$ & $65 \%$ \\
\hline 5 & Índice de investimento em P\& D Total = & $45 \%$ \\
\hline 6 & Índice de horas de treinamento (\%) = & $61 \%$ \\
\hline 7 & Desempenho/meta de qualidade $(\%)=$ & $59 \%$ \\
\hline 8 & Retenção dos empregados $(\%)=$ & $85 \%$ \\
\hline 9 & Eficiência administrativa/receitas $(\%)=$ & $92 \%$ \\
\hline Total $(\%)$ & $\mathbf{6 2 8 \%}$ \\
\hline
\end{tabular}

Fonte: Elaborado pelos autores

No quadro 05, observa-se que foram selecionados diversos índices relacionados ao capital intelectual ligados ao desempenho no mercado, satisfação do cliente, liderança, motivação, pesquisa e desenvolvimento, treinamento, qualidade, retenção de empregados e eficiência de gestão. 
Quadro 06: Gastos relacionados ao capital intelectual

\begin{tabular}{|c|c|c|}
\hline $\mathrm{N}^{\mathrm{o}}$ & Descrição dos gastos relacionados ao capital intelectual & Valor \\
\hline 1 & Receitas resultantes da atuação em novos negócios. & $300.000,00$ \\
\hline 2 & Investimento no desenvolvimento de novos mercados. & $150.000,00$ \\
\hline 3 & Investimento no desenvolvimento do setor industrial. & $500.000,00$ \\
\hline 4 & Investimento no desenvolvimento de novos canais. & $250.000,00$ \\
\hline 5 & $\begin{array}{l}\text { Investimento em Tecnologia da Informação (TI) aplicada a } \\
\text { vendas, serviço e suporte. }\end{array}$ & $80.000,00$ \\
\hline 6 & Investimento em TI aplicado à administração. & $90.000,00$ \\
\hline 7 & Novos equipamentos de TI. & $159.000,00$ \\
\hline 8 & Investimento no suporte aos clientes. & $100.000,00$ \\
\hline 9 & Investimento no serviço aos clientes. & $210.000,00$ \\
\hline 10 & Investimento no treinamento de clientes. & $320.000,00$ \\
\hline 11 & Despesas com clientes não relacionadas ao produto. & $32.000,00$ \\
\hline 12 & 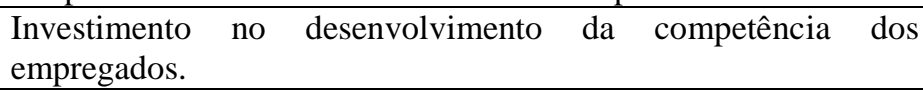 & $150.000,00$ \\
\hline 13 & $\begin{array}{l}\text { Investimento em suporte e treinamento relativo a novos produtos } \\
\text { para os empregados. }\end{array}$ & $85.000,00$ \\
\hline 14 & $\begin{array}{l}\text { Treinamento especialmente direcionado aos empregados que não } \\
\text { trabalham nas instalações da empresa. }\end{array}$ & $25.000,00$ \\
\hline 15 & $\begin{array}{l}\text { Investimento em treinamento, comunicação e suporte } \\
\text { direcionados aos empregados permanentes em período integral. }\end{array}$ & $35.000,00$ \\
\hline 16 & $\begin{array}{l}\text { Programas de treinamento e suporte especialmente direcionados } \\
\text { aos empregados temporários de período integral. }\end{array}$ & $32.500,00$ \\
\hline 17 & $\begin{array}{l}\text { Programas de treinamento e suporte especialmente direcionados } \\
\text { aos empregados temporários de tempo parcial. }\end{array}$ & $15.000,00$ \\
\hline 18 & Investimento no desenvolvimento de parcerias/joint-ventures. & $250.000,00$ \\
\hline 19 & Upgrades no sistema. & $32.000,00$ \\
\hline 20 & Investimento na identificação da marca (logotipo/nome). & $15.000,00$ \\
\hline 21 & Investimento em novas patentes e direitos autorais. & $130.000,00$ \\
\hline \multicolumn{2}{|c|}{ Total } & $2.960 .500,00$ \\
\hline
\end{tabular}

Fonte: Elaborado pelos autores

O valor do capital intelectual é calculado pela seguinte fórmula:

- $\mathrm{x}$ (número de índices $)=9$

- $\mathrm{i}(\mathrm{n} / \mathrm{x})$ percentual $=69,78 \%$

- Valor do Capital Intelectual (Ic) = $2.960 .500,00 \times 69,78 \%$

$=2.065 .771,11$

O capital intelectual, pelas informações do exemplo, tem valor de $\mathrm{R} \$$ 2.065.771,11.

O modelo de Skandia permite analisar quais fatores inferem diretamente no valor do
Capital Intelectual, possibilitando ações da empresa sobre os mesmos.

De acordo com a literatura pesquisada, o modelo de Skandia é o que melhor contribui para enriquecer as Demonstrações Contábeis. Esse modelo apresenta menor subjetividade em relação aos demais e uma padronização na metodologia de cálculo do valor do Capital Intelectual.

Além disso, ele ainda pode ser adaptado à realidade de cada empresa. Tem-se a possibilidade de adicionar ou excluir indicadores. Para finalizar, o modelo sugerido, se adotado pela legislação, seria 
uma metodologia para padronização, comparações e análise do valor do Capital Intelectual das empresas.

\section{CONSIDERAÇÕES FINAIS}

A Contabilidade, com a adoção das Normas Internacionais, passou a ganhar destaque na atividade empresarial como ferramenta de gestão. $\mathrm{O}$ grande desafio para a Ciência Contábil é buscar ferramentas para mensurar o intangível, entre o qual destaca o Capital Intelectual, responsável pela trajetória de crescimento e desenvolvimento da empresa.

O Capital Intelectual é formado pelo conjunto de valores e conhecimento em uma empresa que lhe proporciona vantagem competitiva. Constitui a matéria intelectual como conhecimento, informações, experiências e propriedade intelectual. Embora apresente característica de intangibilidade, não pode ser tocado, pois não possui existência física, mas agrega valores reais à organização, portanto, precisa ser mensurado.

Cabe aos contadores e gestores das empresas adaptarem o que melhor se enquadra no perfil estratégico da empresa. A existência dos métodos para mensuração do Capital Intelectual deixa evidente que há valores "ocultos" nas empresas, além dos valores tangíveis.

Existem diversos métodos na literatura para mensuração do capital intelectual. Entre as apresentadas no artigo, recomenda-se adicionar, de forma complementar, às demonstrações contábeis tradicionais, o modelo de Skandia. Este modelo abrange indicadores sob o foco financeiro, humano, do cliente, do processo e da renovação e desenvolvimento. A contabilidade contribui fortemente com o foco financeiro, fornecendo os índices financeiros, por meio, principalmente, dos dados das Demonstrações Contábeis.

A Contabilidade deve criar e desenvolver técnicas que permitam que o Capital Intelectual seja espelhado de forma clara, simples e objetiva. Uma economia só é forte quando as pessoas que a compõem são eficientes e capazes de agregarem valor aos produtos e serviços. Recomenda-se aos profissionais de Contabilidade estudos adicionais a respeito do método proposto para mensuração do Capital Intelectual.

\section{REFERÊNCIAS}

AFONSO, O. Diffusion and directed technological knowledge, human capital and wages. Economic Modelling, v. 31, p. 370382, 2013.

ANTUNES, M. T. P. Capital intelectual. São Paulo: Atlas, 2000.

BASSAN, C. C. e HAUSCHILDT, R. Mensuração do Capital Intelectual: Um desafio importante para a Contabilidade.

Revista Eletrônica de Contabilidade do Curso de Ciências Contábeis da 
Universidade Federal de Santa Maria - RS. v.1, n 2, p. 91-106, dez/2004 a fev/2005.

BRASIL. Lei n. ${ }^{\circ}$ 11.941/09. Disponível em: <http:

//www.receita.fazenda.gov.br/legislação/Leis/ 2009/lei11941.htm>. Acesso em: $10 \mathrm{de}$ dezembro de 2016.

<http:

. Lei $\mathbf{n}^{\circ}$ 11.638/07. Disponível em:

/www.planalto.gov.br/ccivil_03/_ato2007-

2010/2007/Lei/L11638.htm>. Acesso em: 10

de dezembro de 2016.

BONTIS, N.; FITZENZ, J. Intellectual capital ROI: a causal map of human capital antecedents and consequents.

JournalofIntellectual Capital, v. 3, n. 3, p. 223-247, 2002.

CARVALHO, L. N.; LEMES, S.

Contabilidade internacional para

graduação. São Paulo: Atlas: 2010.

CPC - COMITÊ DE PRONUNCIAMENTOS CONTÁBEIS. CPC 04 - Ativos Intangíveis. 2011 Disponível em:

http://static.cpc.mediagroup.com.br/Documen tos/187_CPC_04_R1_rev\%2008.pdf. Acesso em: 10 de dezembro de 2016.

DOYLE, E. e O'CONNOR, F. Innovation capacities in economies: Relative performance of small open economies.

Research in International Business andFinance, v. 27, n. 1, p. 106- 123, 2013.

EDVINSSON, L.; MALONE, M. S. Capital intelectual: descobrindo o valor real de sua empresa pela identificação de seus valores internos. São Paulo: Makron Books, 1998.

FERREIRA, L. N. Capital intelectual: um estudo exploratório nas empresas de construção Civil do Distrito Federal. 2004. Disponível em:

<http://www.congressousp.fipecafi.org/artigo s42004/254.pdf. Acesso em: 10 de dezembro de 2016.
GOMES, M. J.Análise do modelo de avaliação de intangíveis proposto por Sveiby (1998) em empresas de base tecnológica no Estado de Pernambuco. Dissertação de Mestardo do Programa Multiinstitucional e Inter-Regional em ciências contábeis -

UnB/UFPB/UFPE/UFRN, Recife, 2003 208f. Disponível em : <http://www.unb.br/cca/posgraduacao/mestrado/dissertacoes/mest_dissert _025.pdf > Acesso em: 10 de dezembro de 2016.

MALHOTRA, Y. Integrating knowledge management technologies in organizational business processes: getting real time enterprises to deliver real business performance. Journal of Knowledge Management, v. 9, n. 1, p. 7-28, 2005.

NIYAMA, J. K. Contabilidade internacional. 2 ed. São Paulo: Atlas, 2010.

PADOVEZE, C. L. Aspectos da gestão econômica do capital humano. Revista de Contabilidade do CRC - SP. São Paulo, p. 20, dez de 2000.

SHARABATI, A.A.A.; JAWAD, S. N.; BONTIS, N. Intellectual capital and business performance in the pharmaceutical sector of Jordan. Emerald Group Publishing, Ltd., 2010.

SHIH, K. H.; LIN, C. W.; LIN, B. S. Assessing the quality gap of intellectual capital in banks. Total Quality Management \& Business Excellence, v. 22, n. 3, p. 289303, 2011.

SOUSA, N. A; PINHO, R.Uma análise do Q de Tobin como Proxy para no nível de investimento da firma.2007.Faculdade de Vitória/FUCAPE.Disponível em: $<$ http://www.congressousp.fipecafi.org/artigo s72007/327.pdf >.Acesso em:10 de dezembro de 2016.

STEFANO, N. M.; FILHO, N. C.; FREITAS, M. C. D.; MARTINEZ, M. A. T. Gestão de Ativos Intangíveis: Implicações e Relações da Gestão do Conhecimento e Capital 
Intelectual. Perspectiva em gestão \&

conhecimento. João Pessoa - PA, v.4, n1, p. 22-37, jan./jun. de 2014.

\section{STEWART, T. A. A riqueza do}

conhecimento: o capital intelectual e a nova organização. Rio de Janeiro: Campus, 2002.

Capital intelectual: A nova vantagem competitiva. Rio de Janeiro: Campus, 1998.

STRAIOTO, D. M. G. T. A contabilidade e os ativos que agregam vantagens superiores e sustentáveis de competitividade - o capital intelectual. Revista Brasileira de Contabilidade, n. 124, p. 33-41, Jul/Ago. 2000.

SVEIBY. K. E. A nova riqueza das organizações: gerenciando e avaliando patrimônios de conhecimento. Rio de Janeiro: Campus, 1998.

WADONGO, B.; KAMBONA, O.; ODHUNO, E. Emerging critical generic managerial competencies: A challenge to hospitality educators in Kenya. African Journal of Economic and Management Studies, v. 2, n. 1, p. 56-71, 2011. 